\title{
Inhibitory Effect of Epinephrine on Insulin-stimulated Glucose Uptake by Rat Skeletal Muscle
}

\author{
Jean-Louis Chiasson, Hisataka Shikama, David T. W. Chu, and \\ JoHN H. ExToN, Laboratories for the Studies of Metabolic Disorders, \\ Howard Hughes Medical Institute, Department of Physiology, \\ Vanderbilt University Medical School, Nashville, Tennessee 37232
}

A B S T R A C T The effect of epinephrine on basal and insulin-stimulated glucose uptake in perfused hindlimbs of fed rats was studied. Insulin increased glucose uptake in a dose-dependent manner from a basal value of $1.5 \pm 0.3$ up to a maximum value of $5.3 \pm 0.9 \mu \mathrm{mol} / \mathrm{min}$ per $100 \mathrm{~g}$ with $6 \mathrm{nM}(1 \mathrm{mU} / \mathrm{ml})$. Epinephrine at $10 \mathrm{nM}$ and $0.1 \mu \mathrm{M}$ also increased glucose uptake to $2.6 \pm 0.1$ and $3.1 \pm 0.1 \mu \mathrm{mol} / \mathrm{min}$ per $100 \mathrm{~g}$, respectively. These same concentrations of epinephrine, however, suppressed the insulin-stimulated glucose uptake to $3.2 \pm 0.3 \mu \mathrm{mol} / \mathrm{min}$ per $100 \mathrm{~g}$. Both the stimulatory and inhibitory effects of epinephrine on glucose uptake were completely reversed by propranolol, but were not significantly altered by phentolamine.

Uptake of 3-O-methylglucose and 2-deoxyglucose into thigh muscles of the perfused hindlimbs was stimulated fivefold by insulin, but was unaffected by epinephrine. Epinephrine also did not inhibit the stimulation of uptake by insulin. Epinephrine decreased the phosphorylation of 2-deoxyglucose, however, and caused the intracellular accumulation of free glucose. These last two effects were more prominent in the presence of insulin. Whereas epinephrine caused large rises in glucose-6-P and fructose-6-P, insulin did not alter the concentration of these metabolites either in the absence or presence of epinephrine.

These data indicate that: $(a)$ epinephrine has a stimulatory effect on glucose uptake by perfused rat hindlimbs that does not appear to be exerted on skeletal muscle; $(b)$ epinephrine does not affect hexose transport in skeletal muscle; $(c)$ epinephrine inhibits insulinstimulated glucose uptake in skeletal muscle by inhibiting glucose phosphorylation. It is hypothesized that the inhibition of glucose phosphorylation is due to the stimulation of glycogenolysis, which leads to the

Dr. Chiasson's present address is Institut de Recherches Cliniques de Montreal, Montreal, Quebec, H2W 1R7, Canada.

Received for publication 5 September 1980 and in revised form 29 April 1981. accumulation of hexose phosphates, which inhibit hexokinase.

\section{INTRODUCTION}

Although the effects of epinephrine on muscle glycogen metabolism are well characterized, the actions of the catecholamine on glucose uptake by muscle are poorly defined. Although it is well established that epinephrine administration in vivo is associated with a decrease in glucose clearance (1-6), the in vitro data have not been consistent. Walaas and Walaas (7) showed 30 years ago that epinephrine could decrease glucose uptake in isolated rat diaphragm. Subsequent investigators have noted, however, that this inhibition is consistently seen when the muscle is incubated in phosphatè-buffered medium (8-11), but not when a more physiological bicarbonate-buffered medium is used $(9,11)$.

There has been a limited number of studies of the effects of epinephrine on the transport of nonmetabolized monosaccharides in rat diaphragm and soleus. Newsholme and Randle (12) reported that epinephrine at $0.1 \mathrm{mM}$ moderately increased the uptake of $\mathrm{D}-3-\mathrm{O}$ methylglucose, but not $\mathbf{D}$-xylose in diaphragm. More recently, Bihler and associates $(13,14)$ demonstrated an inhibitory effect of $10 \mathrm{nM}-10 \mu \mathrm{M}$ epinephrine on the transport of 3-O-methylglucose in rat diaphragm and soleus. At very high concentrations $(0.1-1 \mathrm{mM})$ the catecholamine was reported to stimulate transport of the hexose in diaphragm, but not soleus $(13,14)$.

An important aspect of epinephrine action on metabolism is its interaction with insulin. Surprisingly, there have been very few studies of the effects of epinephrine on insulin-stimulated hexose uptake by skeletal muscle in vitro. Walaas (10) originally showed that epinephrine inhibited the effect of insulin on glucose uptake in rat diaphragm. Kipnis and Cori (15) then reported that epinephrine did not inhibit the stimulatory effect of insulin on 2-deoxyglucose uptake by rat diaphragm, but 
did decrease the phosphorylation of the sugar. Newsholme and Randle (12) similarly found that epinephrine did not alter insulin-induced xylose uptake in this tissue.

In almost all the reported studies of epinephrine actions on glucose uptake in muscle, rat diaphragms have been used, and it is not certain that the results are entirely applicable to voluntary skeletal muscle. The purpose of the present study was therefore to characterize the actions of epinephrine in regulating basal and insulin-stimulated glucose uptake by voluntary skeletal muscle using the perfused rat hindlimb preparation. The actions of the catecholamine were further analyzed with respect to changes in glucose transport and phosphorylation.

\section{METHODS}

Hindlimb perfusion preparation and glucose uptake studies. Male rats of the Sprague-Dawley strain (Harland Industries) fed ad lib. and weighing $180-220 \mathrm{~g}$ were used in this study. The hindlimbs were perfused as described by Caldwell et al. (16). The perfusion medium was made up of KrebsHenseleit bicarbonate buffer containing $4 \%$ bovine serum albumin (Pentex fraction V), 30\% washed aged human erythrocytes and $10 \mathrm{mM}$ D-glucose. The flow rate was maintained at $\sim 10 \mathrm{ml} / \mathrm{min}$ with Holter model 911 roller pumps (Extracorporeal Medical Specialties, Inc., King of Prussia, Pa.). The perfusate was recirculated for the first $20 \mathrm{~min}$ to allow equilibration of the preparation. This was then followed by a $30-\mathrm{min}$ experimental perfusion period performed with nonrecirculation of medium. During the experimental period, a $0.9 \% \mathrm{NaCl}$ solution containing $0.1 \%$ bovine serum albumin with or without hormones (insulin and/or epinephrine) was infused into the aortic line at $0.2 \mathrm{ml} / \mathrm{min}$ by means of a Harvard model 940 infusion pump (Harvard Apparatus Co., Inc., South Natick, Mass.). When adrenergic blockers were used, they were added to the perfusate as a single bolus and allowed to equilibrate throughout the system $10 \mathrm{~min}$ before hormone infusion. Plasma glucose and whole blood lactate, $\mathrm{pO}_{2}$ and $\mathrm{pH}$ were monitored in the arterial and venous samples drawn at 10-min intervals throughout the study.

Studies of 2-deoxyglucose and 3-O-methylglucose uptake. In studies of the uptake of nonmetabolized sugars, the protocol described for the glucose uptake studies was followed with the following modifications. At 30 or $40 \mathrm{~min}$, i.e., 10 or 20 min after the commencement of hormone infusion, infusion of $\left[{ }^{14} \mathrm{C}\right]$ sucrose (final activity, $0.01 \mu \mathrm{Ci} / \mathrm{ml}$ ) was begun together with either $\left[{ }^{3} \mathrm{H}\right] 2$-deoxyglucose or $\left[{ }^{3} \mathrm{H}\right] 3-\mathrm{O}$-methylglucose (final activity, $0.1 \mu \mathrm{Ci} / \mathrm{ml}$ ). At the end of the experimental period, i.e., 10 or 30 min later, a sample of thigh muscle was rapidly excised and frozen. Simultaneously, perfusate samples were taken from both arterial and venous lines. The radioactivity of sucrose and nonmetabolized sugars was determined in perfusate and muscle samples according to Saitoh et al. (17). The intracellular spaces for the nonmetabolizable sugars were calculated by subtracting the sucrose space from their total tissue spaces. It was assumed that equilibrium of sugars between the perfusate and extracellular tissue compartment was complete during the $10-$ or $30-\mathrm{min}$ infusion period. This seems likely because tissue $\left[{ }^{14} \mathrm{C}\right]$ sucrose radioactivity reached a steady value at this time corresponding to a space of $157 \pm 10 \mu \mathrm{l} / \mathrm{g}$ of muscle. Whereas insulin did not alter the tissue sucrose space, epinephrine increased it to $204 \pm 11 \mu \mathrm{l} / \mathrm{g}$ of muscle.
In the experiments with $\left[{ }^{3} \mathrm{H}\right] 2$-deoxyglucose, the frozen muscle samples were pulverized, deproteinized with $5 \%$ $\mathrm{HClO}_{4}$, and centrifuged. The supernatant fluids were neutralized and chromatographed on Dowex $1 \times 8\left(\mathrm{Cl}^{-}\right.$form $)$ according to Olefsky (18). Free $\left[{ }^{3} \mathrm{H}\right] 2$-deoxyglucose was eluted with water and $\left[{ }^{3} \mathrm{H}\right]$ deoxyglucose-6- $\mathrm{P}$ with $0.2 \mathrm{M}$ formic acid/0.5 M ammonium formate ( $\mathrm{pH} 4.9)$. Aliquots of the two fractions were mixed with ACS scintillation fluid (Amersham Corp., Arlington Heights, Ill.) and counted in a doublechannel spectrometer to give ${ }^{3} \mathrm{H}$ and ${ }^{14} \mathrm{C}$ radioactivities.

Analytical methods. Serum glucose was determined by the glucose oxidase technique with a Beckman glucose analyzer (Beckman Instruments, Inc., Fullerton, Calif.). Glucose utilization was calculated from the measured perfusate flow rate and the average arterio-venous concentration difference measured over the 30-min experimental period. Blood $\mathrm{pH}$ and $\mathrm{pO}_{2}$ were measured with the BMS3 MR2 Blood Gas Analyzer from Radiometer Co., Copenhagen, Denmark. These parameters were monitored to determine whether preparations were adequately perfused.

For measurement of intracellular free glucose and glycolytic intermediates, thigh muscle tissue was freeze-clamped at the temperature of liquid $\mathrm{N}_{2}$ and pulverized at this temperature in a percussion mortar. Aliquots of frozen powder were homogenized in ice-cold $5 \% \mathrm{HClO}_{4}$ (containing $4 \mathrm{mM}$ NaEDTA) and centrifuged. The supernates were neutralized with $3 \quad \mathrm{M} \mathrm{K}_{2} \mathrm{CO}_{3}$ and assayed enzymatically for glucose (19), glucose-6-P and fructose-6-P (20), and fructose-1,6- $P_{2}$ and triose-P (21). Tissue glucose values were corrected for extracellular glucose which was determined from the tissue sucrose space and the perfusate plasma glucose concentration.

Statistical analysis of results. All statistical variations cited in the text are standard errors of the mean. Statistical analyses were carried out with Student's $t$ test (22)

Materials. Insulin was purchased from Eli Lilly Laboratories (Indianapolis, Ind.) and (-)-epinephrine bitartrate and (+)-propranolol $\mathrm{HCl}$ from Sigma Chemical Co., St. Louis, Mo. Phentolamine mesylate was from Ciba-Geigy Corporation (Summit, N. J.) and serum bovine albumin, Pentex, fraction V, was from Miles Laboratories, Elkhart, Ind. Enzymes and coenzymes used in the determination of lactate and tissue metabolites were obtained from Boehringer Mannheim Biochemicals, Indianapolis, Ind. 2-[1,2- $\left.{ }^{3} \mathrm{H}\right]-$ deoxy-D-glucose, 3-O-[methyl $\left.-{ }^{3} \mathrm{H}\right]$ methyl-D-glucose, and $\left[\mathrm{U}-{ }^{14} \mathrm{C}\right]$ sucrose were obtained from New England Nuclear, Boston, Mass.

\section{RESULTS}

Effects of insulin and epinephrine added alone on glucose uptake by perfused rat hindlimbs. Fig. 1A shows the response of glucose uptake by perfused rat hindlimbs to several concentrations of insulin. Insulin at $0.01 \mathrm{mU} / \mathrm{ml}(60 \mathrm{pM})$ was without effect, but at 0.1 $\mathrm{mU} / \mathrm{ml}(0.6 \mathrm{nM})$ it increased glucose uptake from a basal value of $1.5 \pm 0.3$ to $2.9 \pm 0.2 \mu \mathrm{mol} / \mathrm{min}$ per $100 \mathrm{~g}$ of body wt $(P<0.01)$. Maximal stimulation (to $5.3 \pm 0.9$ $\mu \mathrm{mol} / \mathrm{min}$ per $100 \mathrm{~g}$ ) was observed with $1 \mathrm{mU} / \mathrm{ml}$ $(6 \mathrm{nM})$ insulin.

In contrast to the in vivo effect of epinephrine on the clearance of glucose (1-6), increasing concentrations of the hormone resulted in a stimulation of basal glucose uptake by the perfused hindlimb that was significant at $10 \mathrm{nM}$ and $0.1 \mu \mathrm{M}$ (Fig. $1 \mathrm{~B}, P<0.05$ and $P<0.01$, respectively). The effect was maximal between 10 and 30 min (data not shown). A lower concentration ( $1 \mathrm{nM}$ ) 

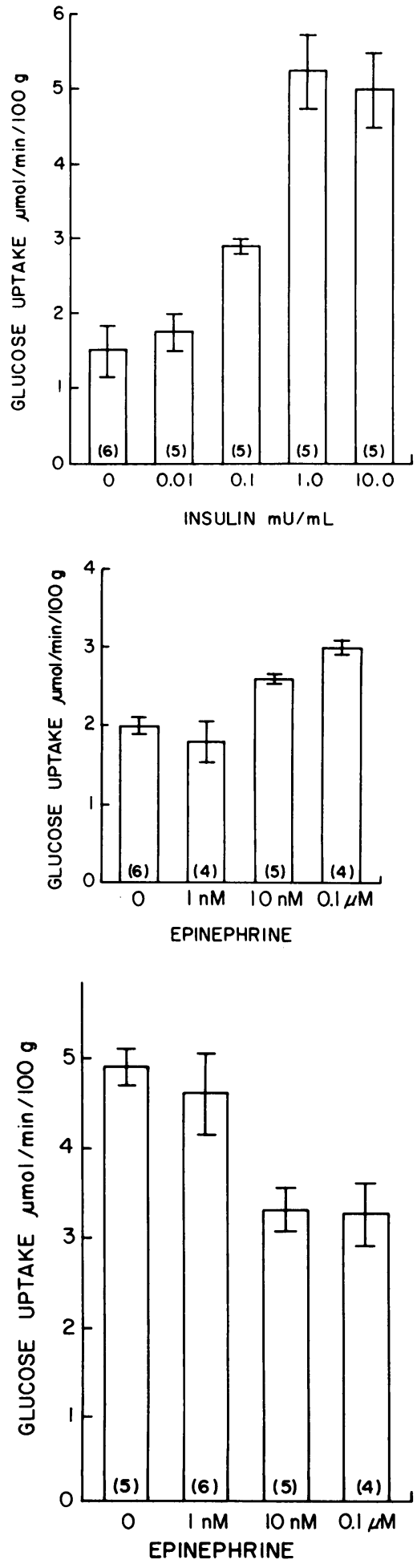

FIGURE 1 (A) Stimulatory effect of increasing insulin concentrations of insulin on glucose uptake by hindlimbs of fed rats. Hindlimbs were initially perfused for $20 \mathrm{~min}$ with recirculating medium containing $10 \mathrm{mM}$ glucose and then for 30 min with the same medium with nonrecirculation. Saline or insulin was infused during the phase of nonrecirculation. had no demonstrable effect on glucose uptake. Concentrations higher than $0.1 \mu \mathrm{M}$ were not tested since perfusions with these concentrations were unsatisfactory, owing to a high incidence of edema. ${ }^{1}$

Inhibitory effect of epinephrine on insulin-stimulated glucose uptake by perfused rat hindlimbs. In contrast to its effects on basal glucose uptake, epinephrine had an inhibitory effect on glucose uptake by the perfused rat muscle if this process was stimulated by $1 \mathrm{mU} / \mathrm{ml}$ insulin (Fig. 1C). Epinephrine at $1 \mathrm{nM}$ again had no demonstrable effect on the insulinstimulated glucose uptake by the muscle. Increasing the concentration to $10 \mathrm{nM}$, however, resulted in a suppression of the stimulated glucose uptake from $4.9 \pm 0.2$ to $3.3 \pm 0.2 \mu \mathrm{mol} / \mathrm{min}$ per $100 \mathrm{~g}$ of body wt $(P<0.01)$. At a higher epinephrine concentration $(0.1 \mu \mathrm{M})$, the insulin-stimulated glucose uptake could not be suppressed lower than $3.2 \pm 0.3 \mu \mathrm{mol} / \mathrm{min}$ per $100 \mathrm{~g}$, which is not different from the epinephrinestimulated glucose uptake in the absence of insulin $(3.0 \pm 0.1 \mu \mathrm{mol} / \mathrm{min}$ per $100 \mathrm{~g}$, Fig. $1 \mathrm{~B}, P>0.25)$. Studies (not shown) of the time-course of the inhibitory effect of $0.1 \mu \mathrm{M}$ epinephrine on glucose uptake in hindlimbs perfused with $1 \mathrm{mU} / \mathrm{ml}$ insulin showed that inhibition was evident at $10 \mathrm{~min}$ and maximal between 20 and $30 \mathrm{~min}$.

Effects of adrenergic blockers on the effects of epinephrine on glucose uptake by perfused rat hindlimbs. To determine the nature of the adrenergic receptor(s) mediating the effects of epinephrine on glucose uptake by skeletal muscle, the effects of the $\beta$-blocker propranolol and $\alpha$-blocker phentolamine were tested. It was found that when propranolol was administered at $1 \mu \mathrm{M}$, both the stimulatory and inhibitory effects of epinephrine were abolished (Fig. 2). On the other hand, phentolamine at $1 \mu \mathrm{M}$ did not significantly alter the stimulatory $(P>0.05)$ or inhibitory $(P>0.10)$ effects of epinephrine. Thus, both effects of the catecholamine are mediated primarily by $\beta$ adrenergic receptors. Addition of either blocker alone did not affect basal glucose uptake (data not shown).

\footnotetext{
${ }^{1}$ With epinephrine concentrations of $0.1 \mu \mathrm{M}$ or lower, the perfusate flow rate and arterial and venous $\mathrm{O}_{2}$ tensions were unchanged from control values and there was no increase in hindlimb weight. (M. R. Dietz and J. H. Exton. Unpublished observations).
}

Values shown in this and subsequent figures are means $\pm \mathrm{SE}$ and the numbers of experiments are in parentheses. $(B)$ Stimulatory effect of increasing concentrations of epinephrine on glucose uptake by rat hindlimbs. Experimental conditions were as in $(A) .(C)$ Inhibitory effect of increasing concentration of epinephrine on insulin-stimulated $(1 \mathrm{mU} / \mathrm{ml})$ glucose uptake by rat hindlimbs. Experimental conditions were as in $(A)$. 


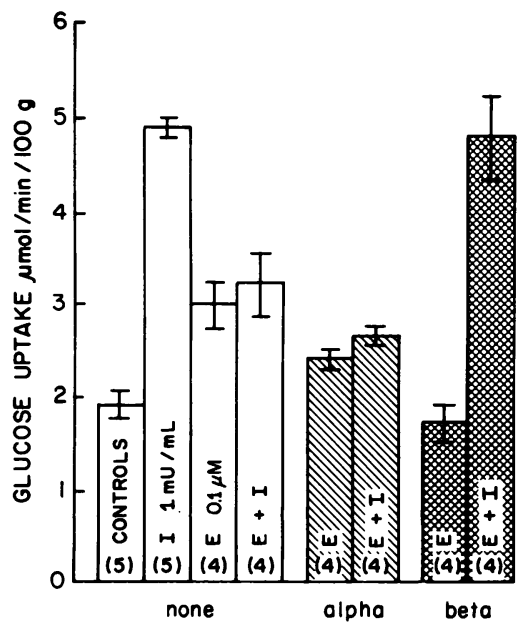

BLOCKERS I $\mu \mathrm{M}$

FIGURE 2 Effects of adrenergic blockers on the stimulatory and inhibitory effects of epinephrine on glucose uptake by rat hindlimbs. Experimental conditions were as in Fig. 1. The $\alpha$-blocker was phentolamine and the $\beta$-blocker was propranolol. They were added to the perfusate $10 \mathrm{~min}$ before the infusion of hormones. I designates insulin and $\mathrm{E}$ designates epinephrine.

Effects of insulin and epinephrine on the uptake and phosphorylation of 2-deoxyglucose in skeletal muscle. Although skeletal muscle is probably the major glucose-utilizing tissue in the hindlimb (23), the preceding studies did not identify this tissue as the site at which epinephrine was controlling glucose uptake. Nor did they define whether the catecholamine was altering glucose uptake by acting on glucose transport or phosphorylation. To gain information on these points, the uptake and phosphorylation of the glucose analogue $\left[{ }^{3} \mathrm{H}\right] 2$-deoxy-D-glucose in muscle was investigated. This hexose is converted to 2-deoxyglucose-6-P but is not further metabolized in muscle. The uptake of this compound was approximately linear over $30 \mathrm{~min}$ and was inhibited by increasing concentrations of glucose (data not shown). Fig. 3 shows the effects of hormones on the intracellular accumulation of $\left[{ }^{3} \mathrm{H}\right] 2-$ deoxyglucose (free plus phosphorylated forms) during 10 and $30 \mathrm{~min}$. As expected, insulin $(1 \mathrm{mU} / \mathrm{ml})$ stimulated the uptake of the hexose approximately sixfold, but epinephrine $(0.1 \mu \mathrm{M})$ produced no significant effect on uptake in the absence of insulin at either 10 or $30 \mathrm{~min}$. At $30 \mathrm{~min}$, the catecholamine inhibited the action of insulin $(P<0.01)$, but this effect was not significant at $10 \mathrm{~min}(P>0.5)$.

When free $\left[{ }^{3} \mathrm{H}\right] 2$-deoxyglucose was separated from $\left[{ }^{3} \mathrm{H}\right] 2$-deoxyglucose-6-P by ion-exchange chromatography (Methods), more striking effects of epinephrine were seen (Fig. 3). In control and insulin-treated tissues, the hexose was mainly in the phosphorylated

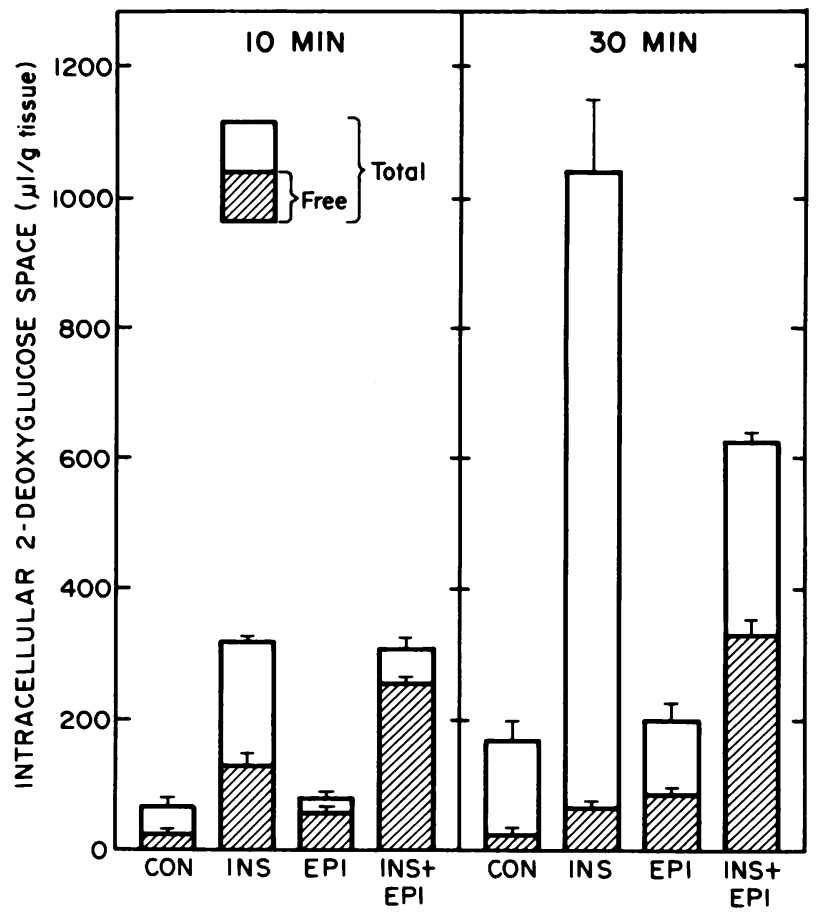

FIGURE 3 Effects of insulin and epinephrine on uptake and phosphorylation of 2-deoxyglucose by muscle of perfused rat hindlimbs. Hindlimbs were initially perfused for $20 \mathrm{~min}$ with recirculating medium containing no added glucose. Insulin $(1 \mathrm{mU} / \mathrm{ml})$ and epinephrine $(0.1 \mu \mathrm{M})$ alone or in combination were then infused for $10 \mathrm{~min}$ (right panel) or $20 \mathrm{~min}$ (left panel) before commencing infusion of $\left[{ }^{3} \mathrm{H}\right] 2$-deoxyglucose and $\left[{ }^{14} \mathrm{C}\right]$ sucrose. Samples of thigh muscles were frozen $10 \mathrm{~min}$ later (left panel) or $30 \mathrm{~min}$ later (right panel). Samples were analyzed for $\left[{ }^{3} \mathrm{H}\right] 2$-deoxyglucose, $\left[{ }^{3} \mathrm{H}\right] 2$ deoxyglucose-6-P, and $\left[{ }^{14} \mathrm{C}\right]$ sucrose as described in Methods. Intracellular $\left[{ }^{3} \mathrm{H}\right] 2$-deoxyglucose was calculated as described in Methods. Values are from four experiments in each case.

form at both 10 and $30 \mathrm{~min}^{2}$ In the presence of epinephrine, however, there was an increase in the free form. Most strikingly, epinephrine reversed the phosphorylation pattern seen with insulin, i.e., it suppressed the phosphorylation of the hexose. Essentially identical data were obtained when 1 or $10 \mathrm{mM}$ glucose was also present in the medium, except that the uptake of 2-deoxyglucose was lower (data not shown). These data thus suggested that although epinephrine did not inhibit the stimulatory effect of insulin on hexose transport, it inhibited the phosphorylation of hexose.

Effects of insulin and epinephrine on the uptake of 3-O-methylglucose in skeletal muscle. To confirm

\footnotetext{
${ }^{2}$ In this series of experiments, the fraction of intracellular 2-deoxyglucose in the free form in the muscles perfused with insulin for $10 \mathrm{~min}$ was higher than that seen in two other series, in which insulin, but not epinephrine, was tested. In these, the percentage of the sugar in the free form was $<10 \%$ of total.
} 
the preceding indication that epinephrine did not alter hexose transport in muscle, further experiments with the nonmetabolized glucose analogue 3-O- $\left[{ }^{14} \mathrm{C}\right]$ methylglucose were performed. The uptake of this sugar increased during $30 \mathrm{~min}$ and was inhibited by glucose (data not shown). Fig. 4 shows the hormone-induced changes in the intracellular accumulation of 3-Omethylglucose during $10 \mathrm{~min}$. As expected, there was a large stimulation with insulin, but no changes were observed with epinephrine in the absence or presence of insulin.

Changes in intracellular glucose and glycolytic intermediates induced by insulin and epinephrine in skeletal muscle. Since the studies with 2-deoxyglucose pointed to an inhibitory effect of epinephrine on the hexokinase reaction, this was explored further by measuring the intracellular concentrations of free glucose, glucose-6-P, and other glycolytic intermediates in muscle perfused with $10 \mathrm{mM}$ glucose plus insulin and/or epinephrine (Fig. 5). In the control and insulin-treated muscle, free glucose was barely detectable. There was a significant $(P<0.01)$ accumulation of intracellular glucose in the presence of epinephrine

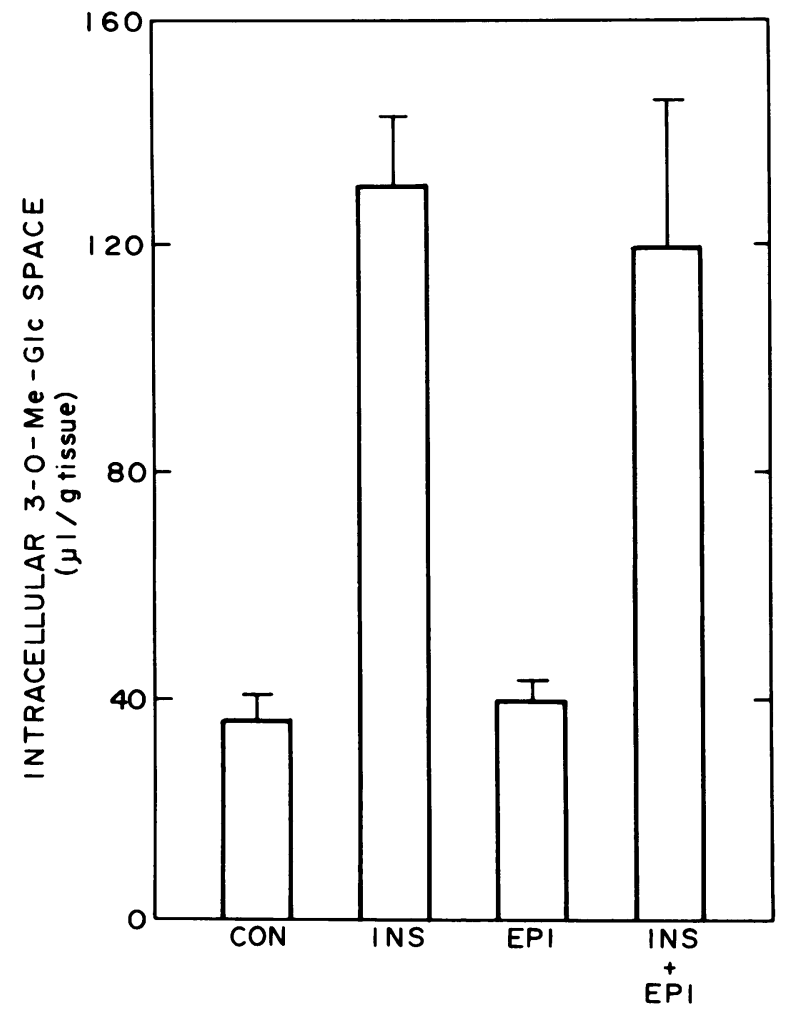

Figure 4 Effects of insulin $(1 \mathrm{mU} / \mathrm{ml})$ and epinephrine $(0.1 \mu \mathrm{M})$ on uptake of 3-O-methylglucose by muscle of perfused rat hindlimbs. Experimental procedures followed those in Fig. 3. Hormones were infused for $20 \mathrm{~min}$ before the $10 \mathrm{~min}$ infusion of sugars. Values are means of three or four experiments.

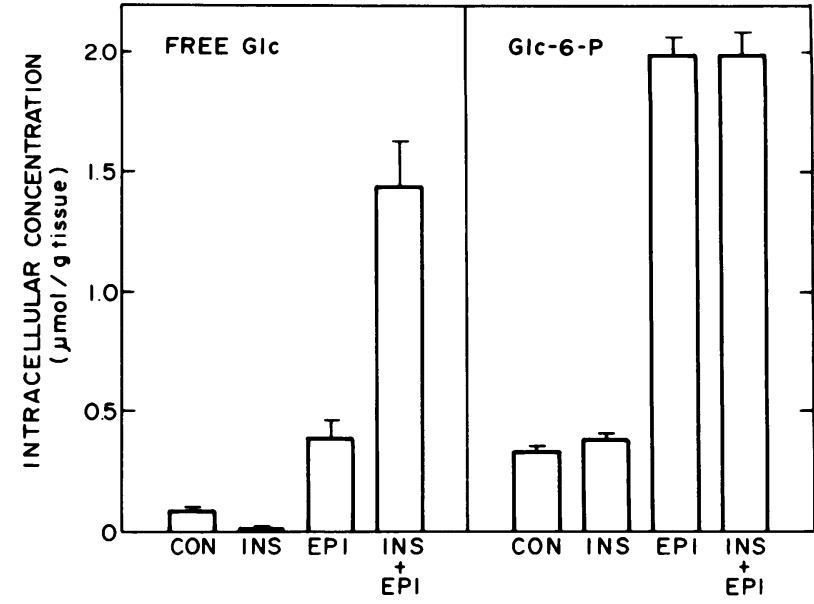

Figure 5 Effects of insulin and epinephrine on intracellular glucose and glucose-6-P in muscle of perfused rat hindlimbs. Experimental conditions were as in Fig. 1. Intracellular glucose and glucose-6-P were determined as described in Methods. Values are means of four to six experiments.

$(0.4 \mu \mathrm{mol} / \mathrm{g})$, however, and this became much greater in the presence of both insulin and epinephrine (1.4 $\mu \mathrm{mol} / \mathrm{g})$. Insulin did not significantly alter the concentration of glucose-6-P when infused alone $(P>0.1)$, whereas epinephrine markedly elevated this. Insulin also did not alter the accumulation of the hexose phosphate induced by epinephrine. Fructose-6-P levels were about one-fifth of those of glucose-6-P, and the hormone-induced changes paralleled those of glucose6-P (data not shown). Fructose-1,6- $\mathrm{P}_{2}$ and triose-P were not altered by insulin, but were increased twofold by epinephrine in the absence or presence of insulin (data not shown). As will be discussed, these findings are consistent with inhibition of glucose phosphorylation by epinephrine due to the accumulation of glucose$6-\mathrm{P}$ resulting from glycogenolysis.

\section{DISCUSSION}

Using the isolated perfused rat hindlimb preparation, we have demonstrated that epinephrine can have both a stimulatory and an inhibitory effect on peripheral glucose uptake. The stimulatory effect of epinephrine was seen on the basal nonstimulated glucose uptake, was mediated by $\beta$-receptors, and was much smaller than the effect of insulin. A key issue raised by the present studies is the tissue site(s) of this effect. As shown in Figs. 3 and 4, we observed no significant stimulation of 3-O-methylglucose or 2-deoxyglucose uptake into muscle by epinephrine. Since transport is generally rate-limiting for glucose uptake in muscle (24), these results suggest that the stimulatory effect of epinephrine on glucose uptake is exerted on another tissue, e.g., adipose tissue. As noted in the Introduction, 
previous reports of the effect of epinephrine on basal glucose uptake by isolated muscle have been inconsistent. Studies of the transport of nonmetabolized glucose analogs into rat diaphragm or soleus have also given variable results. At very supraphysiological concentrations (0.1-1 $\mathrm{mM}$ ) epinephrine has been observed to have a stimulatory effect on the uptake of

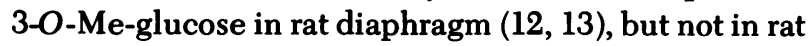
soleus muscle (14). At more physiological concentrations (10 $\mathrm{nM}-0.1 \mu \mathrm{M})$, however, the catecholamine has been noted to exert an inhibitory effect $(12,13)$. Unless there is a gross difference between the epinephrine sensitivity of rat diaphragm and skeletal muscle, these findings lend further support to the idea that muscle is not the site of the stimulatory effect of $10 \mathrm{nM}-0.1 \mu \mathrm{M}$ epinephrine on glucose uptake observed in the present study. ${ }^{3}$

Epinephrine was observed by early investigators to stimulate glucose uptake by adipose tissue $(27,28)$. More recently, Ludvigsen et al. (29) have shown a stimulatory effect of the catecholamine on $3-\mathrm{O}-\mathrm{Me}$ glucose uptake in isolated rat adipocytes incubated in a bicarbonate buffer system, but not a phosphate buffer system. The effect was seen with $10 \mathrm{nM}$ and $0.1 \mu \mathrm{M}$ catecholamine and was inhibited by propranolol. These results indicate that adipose tissue is probably one of the sites at which epinephrine stimulates glucose uptake in the rat hindlimb.

The present findings indicate that the inhibitory effect of epinephrine on insulin-stimulated glucose uptake by the rat hindlimb can be attributed to changes in glucose metabolism in skeletal muscle, although other tissues may also be involved. Such an inhibitory effect on glucose utilization was reported earlier for rat diaphragm $(10,30)$, but has not been observed in adipose tissue $(27,31,32)$. The present investigations indicate that the effect is not exerted on glucose transport. This was most clearly shown in the experiments with 3-O-methylglucose, which is transported on the glucose carrier but is not metabolized. It is also supported by the findings with 2-deoxyglucose, which although it also utilizes the glucose transport system undergoes intracellular phosphorylation without further metabolism. Additional support comes from epinephrine's ability to increase markedly the intracellular concentration of free glucose. This result is contrary to that expected if transport were inhibited.

On the other hand, the present results point to an inhibitory action of epinephrine on glucose phosphorylation. This would explain the accumulation of free glucose and 2-deoxyglucose, especially in the

\footnotetext{
${ }^{3}$ The situation in amphibians may be different from that in mammals since Wohltmann et al. (25) and Saha et al. (26) have reported that epinephrine $(0.1-10 \mu \mathrm{M})$ increases the transport of 3-O-methylglucose in frog sartorius.
}

presence of insulin where hexose entry is enhanced. Inhibition of the hexokinase reaction would also explain epinephrine's ability to decrease the fraction of 2-deoxyglucose in the phosphorylated form (Fig. 3). It is interesting to note that in 1959, Kipnis et al. (33) reached a similar conclusion based on the changes in the concentration of free glucose in diaphragm and gastrocnemius in rats injected with epinephrine. In one animal injected with both epinephrine and insulin, they observed a very large accumulation of intracellular glucose analogous to the present findings. In further studies in vitro, Kipnis and Cori (15) observed that epinephrine did not inhibit the uptake of 2-deoxyglucose by rat diaphragm in the presence of insulin, but that it did decrease the phosphorylation of the sugar. These findings are similar to ours at $10 \mathrm{~min}$. At $30 \mathrm{~min}$ an inhibitory effect of epinephrine on insulin-stimulated glucose or 2-deoxyglucose uptake is evident in our studies, and can be attributed to an increase in sugar efflux consequent to the large increase in intracellular free hexose (relative to that seen with insulin alone).

Epinephrine has also been observed to increase intracellular glucose and to inhibit insulin-stimulated glucose uptake in frog sartorius muscles (25). The rise in intracellular glucose was observed whether or not glucose was present in the external medium. This suggests that it may have been due to the action of amylo-1,6-glucosidase on limit dextrin produced by phosphorylase (34) in addition to inhibition of glucose phosphorylation. Such a mechanism could also contribute to the rise in intracellular glucose seen with epinephrine alone in the present study.

The present findings are entirely consistent with earlier explanations of the inhibitory effect of epinephrine on glucose uptake in muscle, namely that it results from inhibition of the hexokinase reaction due to the large rise in glucose-6-P and fructose-6-P induced by glycogenolysis $(10,15,33)$. In accord with previous findings on glycogenolysis (35), the inhibitory effect of epinephrine on glucose uptake was totally inhibited by $\beta$-adrenergic blockade, but unaffected by $\alpha$-blockade. Furthermore, the inhibitory action of epinephrine on insulin-stimulated glucose uptake developed with a time course similar to that seen for the effect of epinephrine on the level of glucose-6-P (35). Hexokinase from muscle resembles that from other tissues in that it is inhibited by concentrations of glucose-6-P within the range found in muscle in the present study $(36-38){ }^{4}$

\footnotetext{
${ }^{4}$ Some investigators have suggested that the increase in tissue glucose-6-P with epinephrine may not be important in the inhibition of glucose uptake in muscle $(11,39)$. In one study (11), this conclusion was reached on the basis of experiments with cell-free extracts, and no data actually contradicting a role for glucose-6-P were presented. In another study (39), a synthetic inhibitor of cyclic AMP phosphodiesterase
} 
Epinephrine inhibition of insulin-stimulated glucose uptake by muscle would explain the inhibitory effect of the catecholamine on glucose clearance in vivo (1-7). It should be recognized, however, that in the in vivo situation, glucose is taken up by many other tissues in addition to skeletal muscle, and it is likely that changes in some of these, e.g., liver, contribute to the effect. As is found for the inhibitory action of epinephrine on glucose uptake by skeletal muscle in vitro (39, 40, and Fig. 2), the suppression of glucose clearance by epinephrine in vivo is mediated by $\beta$-adrenergic receptors $(2,6)$.

From a physiological viewpoint, the inhibitory effect of epinephrine on insulin stimulation of skeletal muscle glucose uptake is probably an important component of the reversal of insulin-induced hypoglycemia produced by increased sympathetic discharge, and could play a role in the overall regulation of blood glucose by the sympathetic nervous system.

\section{REFERENCES}

1. Cori, C. F., and G. T. Cori. 1928. The mechanism of epinephrine action. J. Biol. Chem. 79: 343-355.

2. Shikama, H., and M. Ui. 1975. Metabolic background for glucose tolerance: mechanism for epinephrine-induced impairment. Am. J. Physiol. 229: 955-961.

3. Rizza, R., M. Haymond, P. E. Cryer, and J. Gerich. 1979. Differential effects of epinephrine on glucose production and disposal in man. Am. J. Physiol. 237: E356E362.

4. Sacca, L., R. Sherwin, and P. Felig. 1978. Effect of sequential infusions of glucagon and epinephrine on glucose turnover in the dog. Am. J. Physiol. 235: E287E290.

5. Deibert, D. C., and R. A. Defronzo. 1980. Epinephrineinduced insulin resistance in man. J. Clin. Invest. 65: 717-721.

6. Rizza, R. A., P. E. Cryer, M. W. Haymond, and J. E. Gerich. 1980. Adrenergic mechanisms for the effects of epinephrine on glucose production and clearance in man. $J$. Clin. Invest. 65: 682-689.

7. Walaas, O., and E. Walaas. 1950. Effect of epinephrine on rat diaphragm. J. Biol. Chem. 187: 769-776.

8. Bouman, P. R., and W. Dermer. 1960. Carbohydrate metabolism in the isolated diaphragm of adrenalectomized rats as affected by exposure to adrenaline in vivo and in vitro. Acta Endocrinol. 35: 551-559.

9. Herman, M. S., and E. R. Ramey. 1960. Epinephrine action on glucose uptake by rat diaphragm: effect of ionic composition. Am. J. Physiol. 199: 226-228.

was employed. This compound was found to inhibit glucose uptake in both the absence and presence of medium $\mathrm{Ca}^{2+}$, although its effects on phosphorylase $a$ and glucose-6-P levels were much less in the absence than in the presence of $\mathrm{Ca}^{2+}$ Inspection of the data, however, suggests that the change in glucose-6-P observed in the absence of $\mathrm{Ca}^{2+}$ might have been sufficient to inhibit glucose utilization. In addition, the possibility that the phosphodiesterase inhibitor might have inhibited glucose transport or phosphorylation by a mechanism (or mechanisms) not involving cyclic AMP was not considered.
10. Walaas, E. 1955. The effect of adrenaline on the uptake of glucose, mannose, and fructose in rat diaphragm. Acta Physiol. Scand. 35: 109-125.

11. Ui, M. 1965. Action of epinephrine on muscle glucose uptake depending on $\mathrm{Ca}^{++}$and phosphate. Am. J. Physiol. 209: 359-364.

12. Newsholme, E. A., and P. J. Randle. 1961. Regulation of glucose uptake by muscle, V. Effects of anoxia, insulin, adrenaline and prolonged starvation on concentrations of hexose phosphates in isolated rat diaphragm and perfused isolated rat heart. Biochem. J. 80: 655-662.

13. Bihler, I., P. C. Sawh, and I. G. Sloan. 1978. Dual effect of adrenaline on sugar transport in rat diaphragm muscle. Biochim. Biophys. Acta. 510: 349-360.

14. Sloan, I. G., P. C. Sawh, and I. Bihler. 1978. Influence of adrenaline on sugar transport in soleus, a red skeletal muscle. Mol. Cell. Endocr. 10: 3-12.

15. Kipnis, D. M., and C. R. Cori. 1959. Studies of tissue permeability. V. The penetration and phosphorylation of 2-deoxyglucose in the rat diaphragm. J. Biol. Chem. 234: 171-177.

16. Caldwell, M. D., W. W. Lacy, and J. H. Exton. 1978. Effects of adrenalectomy on the amino acid and glucose metabolism of perfused rat hindlimbs.J. Biol. Chem. 253: 6837-6844.

17. Saitoh, Y., K. Itaya, and M. Ui. 1974. Adrenergic $\alpha$ receptor-mediated stimulation of the glucose utilization by isolated rat diaphragm. Biochim. Biophys. Acta. 343: 492-499.

18. Olefsky, J. M. 1978. Mechanisms of the ability of insulin to activate the glucose-transport system in rat adipocytes. Biochem. J. 172: 137-145.

19. Bergmeyer, H. U., E. Berndt, F. Schmidt, and H. Stork. 1974. D-Glucose. Determination with hexokinase and glucose-6-phosphate dehydrogenase. In Methods of Enzymatic Analysis. H. U. Bergmeyer, editor Academic Press, Inc., New York. pp. 246-252.

20. Hohorst, J. H. 1963. D-Glucose-6-phosphate and Dfructose-6-phosphate. Determination with glucose-6phosphate dehydrogenase and phosphoglucose isomerase. In Methods of Enzymatic Analysis H. U. Bergmeyer, editor. Academic Press, Inc., New York. pp. 1196-1201.

21. Bucher, T., and J. H. Hohorst. 1963. Dihydroxyacetone phosphate, fructose-1,6-diphosphate and D-glyceraldehyde-3-phosphate. Determination with glycerol-1-phosphate dehydrogenase, aldolase and triosephosphosphate isomerase. In Methods of Enzymatic Analysis H. U. Bergmeyer, editor. Academic Press, Inc., New York. pp. 246-252.

22. Snedecor, G. W., and W. G. Cochran. 1967. Statistical Methods. Iowa State University Press, Ames, Iowa. 6th edition.

23. Ruderman, N. B., C. R. S. Houghton, and R. Hems. 1971 Evaluation of the isolated perfused rat hindquarter for the study of muscle metabolism. Biochem. J. 124: 639651.

24. Park, C. R., O. B. Crofford, and T. Kono. 1968. Mediated (nonactive) transport of glucose in mammalian cells and its regulation. J. Gen. Physiol. 52: 296-318.

25. Saha, J., R. Lopez-Mondragon, and H. T. Narahara. 1968. Effect of epinephrine on permeability to sugar and on the production of free glucose in skeletal muscle. J. Biol. Chem. 243: 521-527.

26. Wohltmann, H. J., H. T. Narahara, and M. E. Wesley. 1967. Specificity of the effects of insulin on permeability of frog sartorius muscles to sugar. Diabetes. 16: 26-34. 
27. Cahill, G. F., Jr., B. Leboeuf, and R. B. Flinn. 1960. Studies on rat adipose tissue in vitro. IV. Effect of epinephrine on glucose utilization. J. Biol. Chem. 235: 1246-1250.

28. Lynn, W. S., R. M. MacLoed, and R. H. Brown. 1960. Effects of epinephrine, insulin, and corticotrophin on the metabolism of rat adipose tissue. J. Biol. Chem. 235: $1904-1911$.

29. Ludvigsen, C., L. Jarett, and J. M. McDonald. 1980. The characterization of catecholamine stimulation of glucose transport by rat adipocytes and isolated membranes. Endocrinology. 106: 786-790.

30. Groen, J., H. van der Geld, R. E. Bolinger, and A. F. Willebrands. 1958. The anti-insulin effect of epinephrine: its significance for the determination of serum insulin by the rat diaphragm method. Diabetes. 7: 272-277.

31. Hagen, J. H., and E. G. Ball. 1960. Studies on the metabolism of adipose tissue. IV. The effect of insulin and adrenaline on glucose utilization, lactate production, and net gas exchange. J. Biol. Chem. 235: 1545-1549.

32. Flatt, J. P., and E. G. Ball. 1964. Studies on the metabolism of adipose tissue. XV. An evaluation of the major pathways of glucose catabolism as influenced by insulin and epinephrine. J. Biol. Chem. 239: 675-685.

33. Kipnis, D. M., E. Helmreich, and C. F. Cori. 1959. Studies of tissue permeability. IV. The distribution of glucose between plasma and muscle.J. Biol. Chem. 234: 165-170.

34. Cori, G. T., and J. Larner. 1951. Actions of amylo-1,6glucosidase and phosphorylase on glycogen and amylopectin. J. Biol. Chem. 188: 17-29.

35. Dietz, M. R., J.-L. Chiasson, T. R. Soderling, and J. H. Exton. 1980. Epinephrine regulation of skeletal muscle glycogen metabolism. J. Biol. Chem. 255: 2301-2307.

36. Crane, R. K., and A. Sols. 1954. The noncompetetive inhibition of brain hexokinase by glucose-6-phosphate and related compounds. J. Biol. Chem. 210: 597-606.

37. Grossbard, L., and R. T. Schimke. 1966. Multiple hexokinases of rat tissues: purification and comparison of soluble forms. J. Biol. Chem. 241: 3546-3560.

38. Lueck, J. D., and H. J. Fromm. 1974. Kinetics, mechanism, and regulation of rat skeletal muscle hexokinase. J. Biol. Chem. 249: 1341-1347.

39. Davidheiser, S., E. S. Haugaard, and N. Haugaard. 1979. Effects of epinephrine and the cyclic AMP phosphodiestrase inhibitor SQ 20009 on glucose and glycogen metabolism in skeletal muscle. Biochem. Pharmacol. 28: 807-813.

40. Abramson, E. A., and R. A. Arky. 1968. Role of betaadrenergic receptors in counterregulation to insulininduced hypoglycemia. Diabetes. 17: 141-146. 